\title{
OPTIMIZATION METHOD AND SOFTWARE FOR FUEL COST REDUCTION IN CASE OF ROAD TRANSPORT ACTIVITY
}

\author{
GyÖRGY KovÁCS
}

\author{
Institute of Logistics, University of Miskolc, Miskolc, Hungary \\ correspondence: altkovac@uni-miskolc.hu
}

\begin{abstract}
The transport activity is one of the most expensive processes in the supply chain and the fuel cost is the highest cost among the cost components of transportation. The goal of the research is to optimize the transport costs in case of a given transport task both by the selecting the optimal petrol station and by determining the optimal amount of the refilled fuel. Recently, in practice, these two decisions have not been made centrally at the forwarding company, but they depend on the individual decision of the driver. The aim of this study is to elaborate a precise and reliable mathematical method for selecting the optimal refuelling stations and determining the optimal amount of the refilled fuel to fulfil the transport demands. Based on the elaborated model, new decision-supporting software is developed for the economical fulfilment of transport trips.
\end{abstract}

KEYWORDS: road transport trip; fuel cost saving; petrol station; optimization; software development.

\section{INTRODUCTION}

The volume of the transport activities connected to production and services is increasing constantly, due to the formation of long intercontinental supply chains [1]. Transport companies have to focus on the cost reduction and profitability [2]. This research study is very relevant, because the cost reduction and efficiency improvement is a very important goal for all service providers.

The ratio of the road transport in Europe is $78 \%$ of the total freight volume [3], and because the fuel cost is the highest cost among the cost components of the transportation, every transport company puts a great emphasis on optimizing road transport activities and reducing transport costs.

Recently, in practice, the selection of the petrol stations for refuelling and the amount of the refilled fuel have not been determined centrally at transport companies, but depend on the individual decision of the driver. This can result in wastes for the transport companies.

The goal of the research is to optimize the transport activity both by selecting the optimal petrol station (depending on the fuel price and the distance to the original destination) and by determining the optimal amount of the refilled fuel (only the required amount of the fuel, not more). The result of wrong decisions is that the cost of the consumed fuel is not optimal. This is true in the case of inland routes, but it has even more significance in the case of international routes, when a high amount of fuel is consumed.

This research is absolutely original and unique, because a precise and reliable mathematical model and method are elaborated for determining the optimal refuelling stations and the optimal amount of the loaded fuel. This research is especially innovative, because, based on the elaborated method, a new soft- ware was developed. So, the research topic is not only theoretical, but the elaborated model, method and software can also be used very efficiently and widely in practice for everyday use. Further advantages of the developed software are that it absolutely suits the customer demands and it is very cost effective.

In this study, the fuel cost reduction is showed in a case study by a comparative analysis (Section 8). It can be concluded that the fuel cost of transport trips can be reduced significantly by applying the developed software.

\section{LiterATURE REVIEW}

The author evaluated a lot of literature relating to the cost components and general characteristics of the road freight transport, which provided the theoretical background of this research. There is a great deal of literature discussing the logistical costs $[4,5,6]$ and logistics literature rarely deals with the introduction of transport cost components [7].

There are three different organization methods in the case of the road transportation: simple trips, shuttle trips and round trips $[8,9]$. The most common form of organizing international road transportation is the round trip. The main goal of organizing transport routes is to minimize specific transport costs and reduce the transport lead time $[10,11,12,13]$. Every transport trip departs from the depot of the transport company and goes to the first station where the goods to be transported are loaded, then it proceeds to the next station where the goods are unloaded, then the next loading and the next unloading, etc. After the last station, the vehicle finishes its route at the depot.

Although the existing literature often discusses route optimization and optimizing transport trips and networks $[7,9,11,13]$, there is a gap in the literature 
in the field of fuel optimization of the road transportation. It can be said that there are hardly any materials available in this topic, the optimization task to be solved has not been covered, and this topic is absolutely new.

In the past years, the author has completed several R\&D projects for forwarding companies, therefore, he has practical experience in the field of transportation. This empirical experience initiated the idea of the optimization software, which offers a prompt solution for everyday problems.

\section{TENDENCIES AND CHARACTERISTICS OF ROAD FREIGHT TRANSPORT}

Rapidly changing market environment, global competition and fluctuating customer demands have resulted in more complex networks of supply chains. The value chain is globalized, the cooperation between enterprises has become more dynamic. Due to these factors, the following changes and tendencies can be seen in the transport sector:

- The volume of the transport activities connected to the production and services is constantly growing.

- Cooperation and coordination between the transport modes (rail, road, water and air) are increasing to form faster and more economical transport chains. Advantages and synergies of the different modes can be combined and utilized.

- Transport distances become longer due to the formation of worldwide global supply chains.

- Transport chains and transport trips are optimized.

- The quality of transport activities is increasing.

- The shipping time considered acceptable by the customer is reduced.

- Optimization of the transport coordination and utilization of resources take place.

- Application of IT tools in logistics improves the efficiency of transport activities and ensures better monitoring and tracking.

- Specific transport costs of transport chains are reduced.

- The technology in the transport sector is developed $[2]$.

Recently, the ratio of the road transport in the total transport volume is $78 \%$ in Europe [3]. The remaining volume of the other modes can be seen in Figure 1 .

The goal of the European Union is to decrease the ratio of the road transport and, consequently, the environmental pollution, noise pollution, traffic jams and accidents can be decreased. A further goal is the better utilization of the railway and water transportation. It can be predicted that the intensity of the road transportation will be increasing to a small extent, so the road transport will be the most significant transport

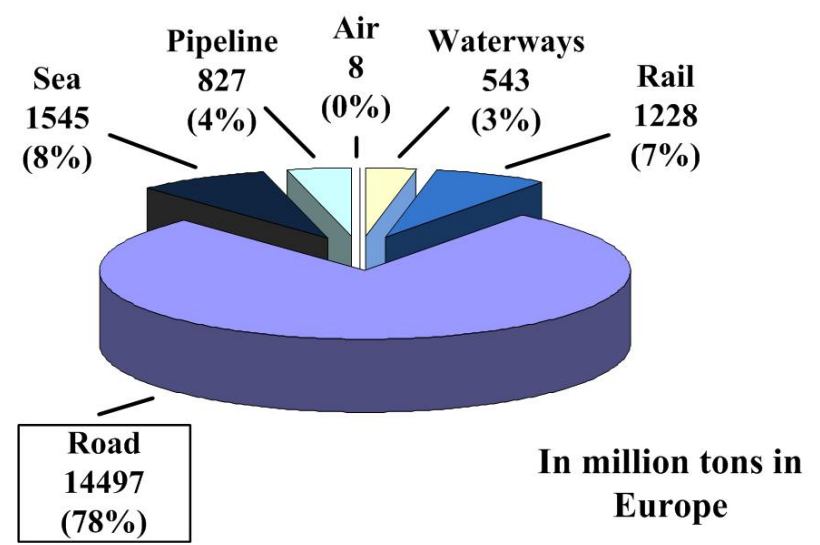

FiguRE 1. Ratio of transport modes in Europe [3].

mode also in the future. Compared to other transport modes, the road transport has many advantages: cheaper mode of transport, shorter transport time, door-to-door service, high density of road network, flexibility in routing and flexibility in time scheduling, and high level of adaptation to the customer's demands.

The optimal operation of transport routes can be attained in the following ways:

- modernization of the vehicle fleet,

- integration of multiple transport tasks into a one transport trip,

- application of multimodal transport modes, where road, railway, and water transportation modes are integrated,

- maximal utilization of vehicles,

- application of IT tools in logistics improves the efficiency of transport tasks, and ensures better monitoring and tracking,

- reduction of fuel costs of the transport tasks: refilling the optimal amount of fuel at the optimal petrol station.

\section{TOTAL PRime COST OF A TRANSPORT TRIP}

At first, we have to define the total prime cost of a transport trip to find the possibilities of the cost reduction. Total prime cost $\left(C_{\mathrm{P} \alpha}\right)$ of the $\alpha$ th transport trip (Figure 2) can be calculated:

$$
C_{\mathrm{P} \alpha}=C_{\mathrm{L} \alpha}+C_{\mathrm{UL} \alpha}+C_{\mathrm{WT} \alpha}+C_{\mathrm{A} \alpha}+C_{\mathrm{W} \alpha}+C_{\mathrm{M} \alpha},
$$

where $C_{\mathrm{L} \alpha}$ is the cost of a transport way with a useful load; $C_{\mathrm{UL} \alpha}$ is the cost of a transport way without a useful load; $C_{\mathrm{WT} \alpha}$ is the cost of the waiting time; $C_{\mathrm{A} \alpha}$ are total additional costs (the motorway fee, parking fee, etc.); $C_{\mathrm{W} \alpha}$ is the driver's salary; $C_{\mathrm{M} \alpha}$ is the maintenance cost of vehicles; $\alpha$ is an identifier of the transport trip.

Because the aim of the optimization is to minimize the cost of the fuel consumption, the cost of a transport 


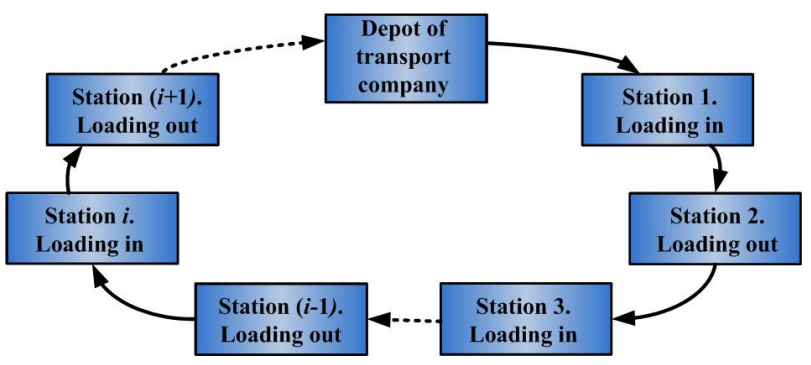

FiguRE 2. Structure of a transport trip.

way with a useful load $\left(C_{\mathrm{L} \alpha}\right)$ and the cost of a transport way without a useful load $\left(C_{\mathrm{UL} \alpha}\right)$ components are examined, the other components can be neglected.

In the calculation, it is advantageous to divide the transport trips $(\alpha)$ into sections $(\beta)$, which means the road between loading-in and loading-out stations (Figure 2). The cost components of the sections are different due to the different volume of transported goods, topography, etc.

The total fuel cost of a transport trip is the sum of the costs of the sections:

$$
C_{\mathrm{F} \alpha}=\sum_{\beta} s_{\alpha \beta} c_{\alpha \beta}[€],
$$

where $s_{\alpha \beta}$ is the distance of $\beta$ th section of $\alpha$ th transport trip $[\mathrm{km}] ; c_{\alpha \beta}$ is the specific cost of the $\beta$ th section of $\alpha$ transport trip $[€ / \mathrm{km}] ; \beta$ is the section identifier; $\alpha$ is the transport trip identifier.

The fuel consumption of a vehicle depends on the fuel consumption of the vehicle without a useful load (main characteristics of the engine) and the weight of the transported useful load. The specific cost can be calculated by

$$
c_{\alpha \beta}=p_{\alpha \beta}\left(f_{f}+\varepsilon^{L} q_{\alpha \beta}\right)[€ / \mathrm{km}],
$$

where $p_{\alpha \beta}$ is the fuel price $[€ / l] ; f_{f}$ is specific fuel consumption in case of an empty vehicle $[1 / \mathrm{km}] ; \varepsilon^{L}$ is the correction factor for different loading conditions (every additional ton of useful load results in extra fuel consumption) $[1 / \mathrm{t} \mathrm{km}] ; q_{\alpha \beta}$ is the transported useful load [t].

The determination of the correction factor is based on the previous research of the author [14].

\section{Optimization of Selecting the IDEAL PETROL STATION AND THE DETERMINATION OF THE AMOUNT OF REFILLED FUEL}

During transport trips (national and international), the selection of the ideal petrol station for refuelling and the amount of the refilled fuel are not determined centrally at most transport companies, but depend on the individual decision of the driver. Therefore, many times refuelling is not carried out at the ideal petrol station, and not the optimal amount of fuel is refilled and, in some cases, the driver refuels absolutely

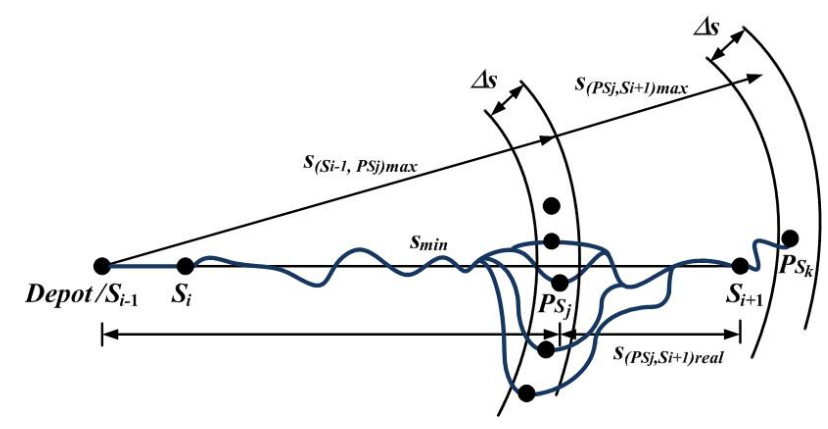

FiguRE 3. Determination of possible petrol stations.

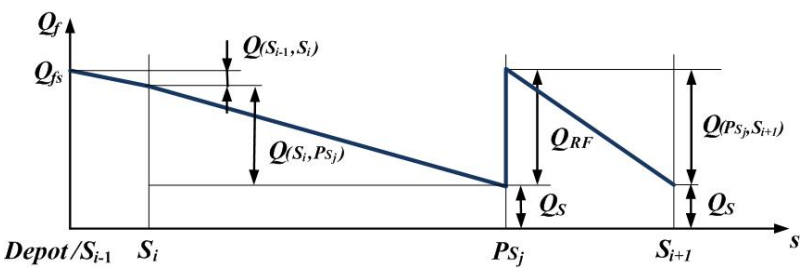

Figure 4. Changes in fuel level during the transport trip.

unnecessarily. The result of these wrong decisions is that the total cost of the transport task and the cost of the consumed fuel are not optimal.

There are many available petrol stations all over Europe, but the difference between the unit prices of the fuel can be $0.16-0.23 € / 1$ at the different the petrol stations, which results in a 115 euro difference in case of a refill of only 500 litres. A common mistake is that the driver refuels at an expensive petrol station, or refuels an unnecessarily high amount of fuel in the end of a transport route before arriving at the depot of the transport company.

The above-mentioned mistakes inspired the author to elaborate a new optimization method for refuelling, which is essential for transportation companies to reduce the transportation costs.

\subsection{Selecting the optimal petrol STATION}

The goal of this study is to determine the most costeffective petrol station (Figure 3) amongst the preferred ones by the company $\left(P S_{j}\right)$, in case of a transportation task from the station $S_{i}$ to the station $S_{i+1}$ defined by GPS coordinates; furthermore, to determine the amount of refilled fuel $\left(Q_{R F}\right)$ with a known initial level of the fuel (Figure 4).

Most transport companies - due to the huge amount of fuel consumption - can buy fuel at a contracted fuel selling company. The GPS coordinates of the available petrol stations and the actual fuel price at the individual stations are provided by the contracted fuel selling company.

The fuel level of the vehicle is known at the starting point $\left(Q_{f s}\right)$, the fuel consumption can be calculated continuously between the loading-in and loading-out stations (Figure 4). 


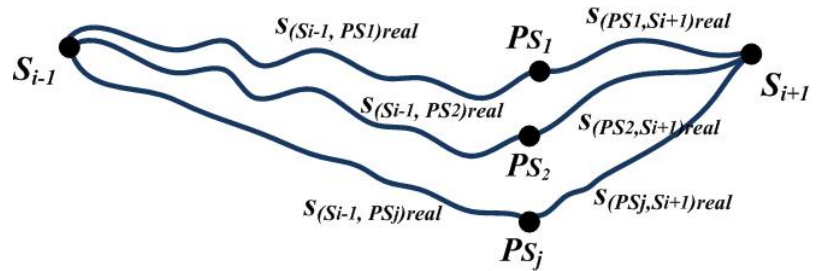

Figure 5. Determination of the optimal refilling station.

There is a constraint relating to the safety amount of fuel capacity $\left(Q_{S}\right)$ which has to be available. Safety amount $Q_{S}$ covers the extra consumption of the vehicle resulting from traffic jams, missed ways, etc. between stations $S_{i-1}$ and $P S_{j}$, and after the station $S_{i+1}$ to find the next petrol station (Figure 4 .

The maximal distance $\left(s_{\max }\right)$, which can be completed by a vehicle, is calculated as follows (see Figure 3]:

$$
s_{\alpha \beta, \max }=\frac{Q_{f s}-Q_{S}}{f_{f}+\varepsilon^{L} q_{\alpha \beta}}[\mathrm{km}] .
$$

The radius $\left(s_{\max }-\Delta s\right)$ defines the coordinates of possible $P S_{j}$ petrol stations, from which the optimal should be selected (Figure 3). The value of $\Delta s$ can be freely defined, relating to the distance from which the optimal petrol station has to be selected before running out of fuel.

The next step is to find the optimal petrol station, which provides the most cost-effective solution (Figure 5). There is a dilemma of whether a cheaper but further or more expensive but nearer refuelling is more cost effective. The increment value of the costs of different refuelling possibilities should be analysed.

Total costs of different alternatives can be calculated by (2) and the following equation (cf. Figure 5):

$C_{\min }=\min \left(c_{S_{i-1}} s_{S_{i-1}, P S_{j}, \text { real }}+c_{P S_{j}} s_{P S_{j}, S_{i+1}, \text { real }}\right)[€]$,

where $c_{S_{i-1}}$ is the specific transport cost taking into consideration the fuel price at petrol station $P S_{j-1}$ $\left[€_{1} / \mathrm{km}\right] ; c_{P S_{j}}$ is the specific transport cost taking into consideration the fuel price at petrol station $P S_{j}$ $[€ / \mathrm{km}] ; s_{S_{i-1}, P S_{j}, \text { real }}$ is the transport way between station $S_{i-1}$ and petrol station $P S_{j}[\mathrm{~km}] ; s_{P S_{j}, S_{i+1} \text {,real }}$ is the transport way between petrol station $P S_{j}$ and station $S_{i+1}[\mathrm{~km}]$.

The optimal solution is the transport way, which has a minimal total cost; it defines the optimal refilling petrol station $\left(P S_{j}\right)$.

\subsection{DETERMINING THE OPTIMAL QUANTITY OF REFILLED FUEL}

A common mistake is that the driver refuels with an unnecessarily high amount of fuel near the end of a transport route before arriving at the depot of the transport company. This can result in extra cost for the transport company. The next aim of this study is to calculate the optimal amount of the refilled fuel required to complete the transport task. The required amount of refilled fuel $\left(Q_{R F}\right)$ can be defined based on Figure 4

$$
\begin{aligned}
Q_{R F}=\left(f_{f}+\varepsilon^{L} q_{\alpha \beta}\right) s_{P S_{j}, S_{i+1}} & \text {,real } \\
& +Q_{S}-Q_{P S_{j}}[1],
\end{aligned}
$$

where $Q_{P S_{j}}$ is the actual fuel level in the vehicle arriving at the selected petrol station; $Q_{S}$ is the safety amount of fuel.

\section{SOFTWARE APPLICATION FOR DETERMINING THE OPTIMAL PETROL STATION AND THE AMOUNT OF FUEL TO BE REFILLED}

Based on the elaborated theoretical model and method, a software was developed for optimizing the fuel supply of transport activities by the contribution of Norbert Cziczer, an engineering student [15]. The software was written in C\# programming language [16] and Microsoft Visual Studio was used to develop the software.

The developed software has two menu points: the "Definition of new data" and "Optimization".

Menu "Definition of new data". In the menu "Definition of new data" we can define:

- new fuel stations (Figure 6);

- new loading in stations and loading out stations (Figure 7);

- new transport vehicles (Figure 8).

Menu “Optimization". Figure 9a provides the possibility of selecting different vehicles for a given transport task. In this menu, the actual fuel level of the vehicle at the beginning of the transport way and the fuel price of this existing fuel can also be input.Figure 9p provides the possibility of defining a transport trip, the loading-in and loading-out stations and the loading conditions (transported weights on the different road sections).Figure 9 s shows the results of the optimization. The total cost of the transport trip, the total fuel consumption of the trip and the remaining fuel volume at the end of the trip are listed.Figure 9d shows the transport way on a map and the location of the optimal petrol station where the driver has to refill the vehicle.Figure 93 shows the name and location of the optimal petrol station and the volume of the fuel to be refilled. The actual fuel price at the ideal petrol station and the total cost of the fuel to be refilled are also listed.

The developed software is capable of selecting the emphoptimal petrol station and determining the optimal amount of refilled fuel during a long transport trip. Based on this information, the drivers can make the best decision and the total cost of the transport trip can be minimized. 


\begin{tabular}{|c|c|c|c|}
\hline \multicolumn{4}{|l|}{ New data } \\
\hline $\begin{array}{l}\text { Add new fuel } \\
\text { station }\end{array}$ & & ew fuel station & \\
\hline $\begin{array}{l}\text { Add new } \\
\text { loading in / out } \\
\text { station }\end{array}$ & & coordinate: & \\
\hline \multirow{2}{*}{$\begin{array}{l}\text { Add new } \\
\text { vehicle }\end{array}$} & & coordinate: & \\
\hline & & uel price [HuF/liter]: & \\
\hline \multicolumn{3}{|r|}{ Add } & \\
\hline Main menu & Optimization & & Exit \\
\hline
\end{tabular}

Figure 6. Definition of new petrol stations.

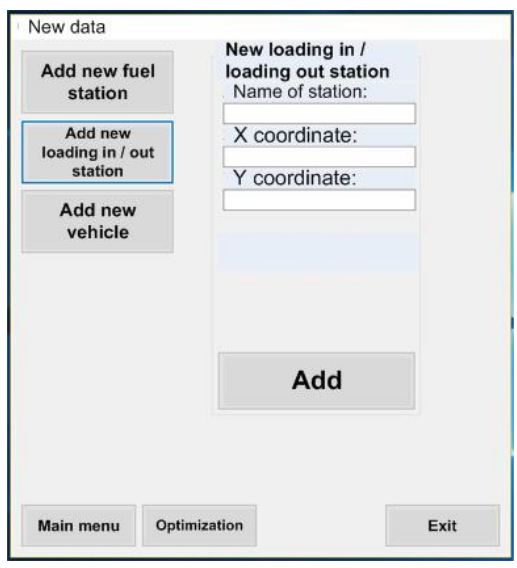

FIGURE 7. Definition of new loading in and loading out stations.

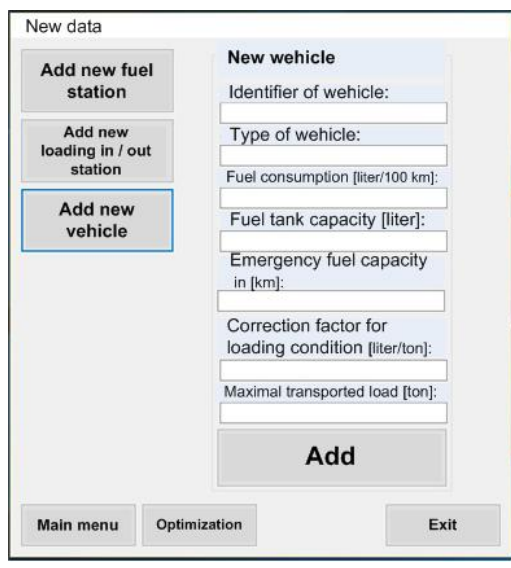

FiguRE 8. Definition of new transport vehicles.

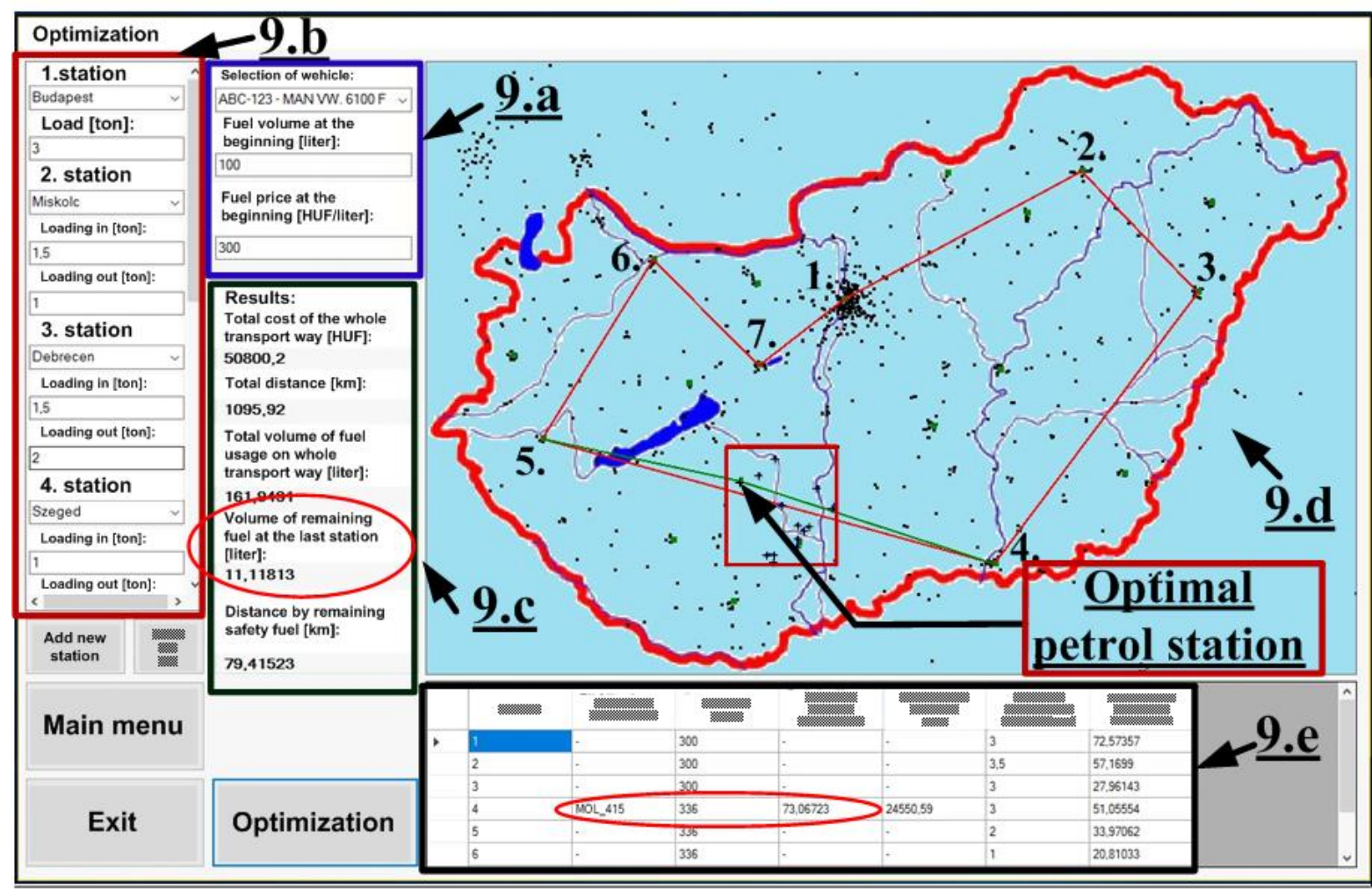

Figure 9. Screen of "Optimization" menu - Optimal solution of the case study.

\section{CASE STUDY - OPTIMIZATION}

\section{USING THE DEVELOPED SOFTWARE}

The transport trip and the loading conditions are (see Figure 10: Station 1 Budapest +3 t; Station 2 Miskolc $+1.5 \mathrm{t}-1 \mathrm{t}$; Station 3 Debrecen $+1.5 \mathrm{t}-2 \mathrm{t}$; Station 4 Szeged $+1 \mathrm{t}-\mathrm{t}$; Station 5 Zalaegerszeg, $+1 \mathrm{t}-2 \mathrm{t}$; Station 6 Győr +2.5 t - 1.5 t; Station 7 Székesfehérvár $+0 \mathrm{t}-1 \mathrm{t}$; Station 8 Budapest $-2 \mathrm{t}$.

In our case, the selected vehicle is a light truck, the fuel consumption is $14 \mathrm{l} / 100 \mathrm{~km}$, maximal fuel tank capacity is 150 litres, the maximal loading capacity is 3.5 tons. The correction factor for different loading conditions is 0.3 (every additional ton of useful load results in $0.3,1 / 100 \mathrm{~km}$ extra fuel consumption).

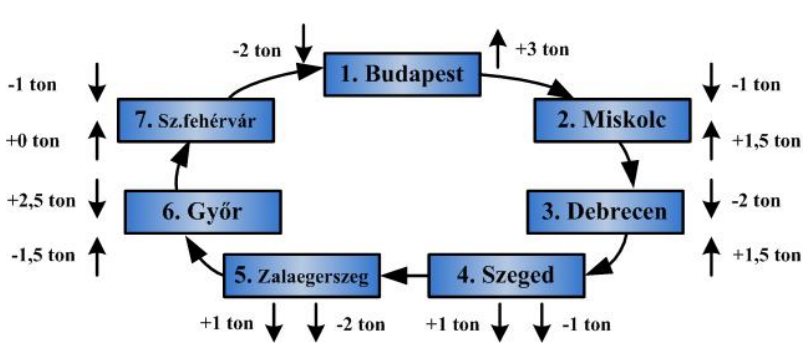

Figure 10. Case study - round trip with loading conditions. 


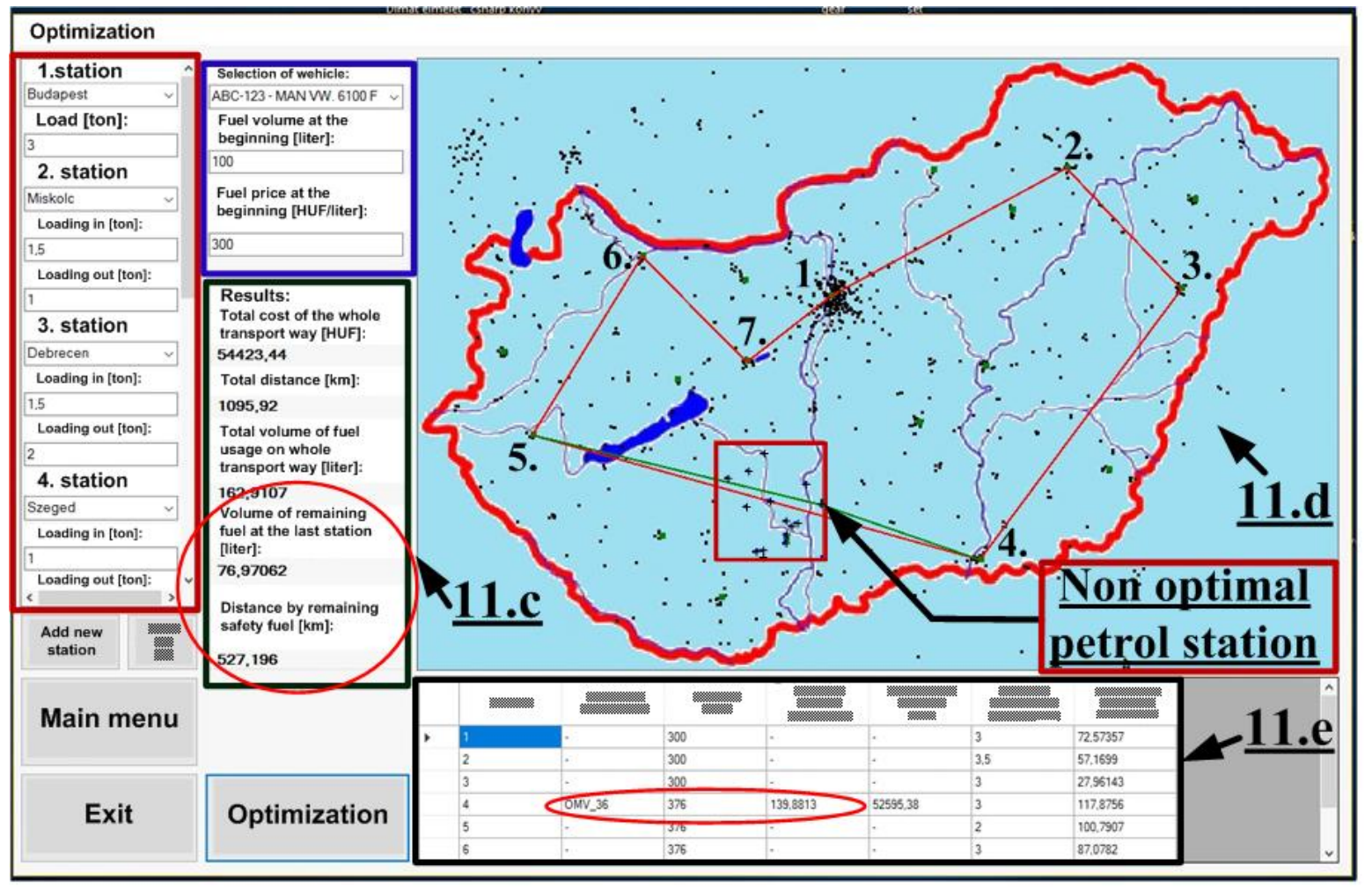

Figure 11. Individual decision of the driver - Non-optimal solution.

The route between the loading-in and loading-out stations can be seen in Figure 9 The fuel volume at the beginning of the tour is 100 litres (see Figure 9a), the stations of the transport way and the loading conditions are given in Figure 9p.

The volume of the fuel will be under the defined limited value before arriving at Station 5 (Figure 9d). The software calculates the optimal petrol station in the searching zone (red rectangle in Figure 9d). The identifier of the optimal station (MOL_415, where the fuel price is minimal: HUF 336/l) and the amount of fuel (73 litres) to be refilled are listed in Figure 9 e.

The conclusion of the optimization can be seen in Figure 9k: the total cost of the whole transport route is HUF 50800, the total volume of the fuel usage on the whole transport trip is 161.9 litres, the volume of the remaining safety fuel at the last station is only 11 litres, which is enough for another $79.4 \mathrm{~km}$.

Currently, the software is under testing, but we hope that in the near future, more and more companies will use it and the total transport costs can be reduced in this way.

\section{Comparative analysis - OPTIMAL RESULT \\ VS. DRIVER DECISION}

The aim of this comparative analysis is to show the cost saving of the optimization resulting from applying the developed software.

There are a lot of possible petrol stations during the transport trip and the selection of the petrol station where the driver refills the vehicle depends on the individual decision of the driver. Therefore, the total cost of the consumed fuel is not optimal, because the fuel prices are different at different petrol stations. In Hungary, for example, the difference between the fuel prices at the cheapest and at the most expensive petrol stations can be $13-19 \%$ in the case of one litre of fuel.

Figure 11 shows a non-optimized (based on a driver's bad decision) result of the same case study detailed in Figure 10 In this case, refuelling is carried out at the most expensive petrol station (depicted in Figure 11de) in the search zone, and the amount of the refilled fuel is 139.8 litres (a full fuel tank capacity of the vehicle). The volume of the remaining fuel at the last station is 76.9 litres (Figure 11; ).

The comparison of the optimal solution (the result of the optimizing software - Figure 9 and the nonoptimal solution (driver's decision - Figure 11) can be seen in Table 1. The results of the driver's wrong decisions are that the total costs of the transport task and the cost of the consumed fuel are not optimal.

It can be seen that if the driver refuels at an expensive petrol station, or refuels with an unnecessarily high amount of fuel at the end of a transport route before arriving at the depot of the transport company a huge extra fuel cost will be incurred.

By applying the developed software, significant cost savings $(-15.85 \%)$ can be attained in case of a short transport trip (Figure 10), but in case of a long international round trip the cost savings can be much higher. 


\begin{tabular}{|c|c|c|c|c|c|c|}
\hline & $\begin{array}{l}\text { Total cost } \\
\text { of the } \\
\text { whole } \\
\text { transport } \\
\text { way [HUF] }\end{array}$ & $\begin{array}{l}\text { Amount of } \\
\text { refilled } \\
\text { fuel }[1]\end{array}$ & $\begin{array}{c}\text { Fuel price } \\
{[\mathrm{HUF} / \mathrm{l}]}\end{array}$ & $\begin{array}{l}\text { Volume of } \\
\text { remaining } \\
\text { fuel at last } \\
\text { station [1] }\end{array}$ & $\begin{array}{c}\text { Cost of } \\
\text { remaining } \\
\text { fuel at last } \\
\text { station } \\
{[\mathrm{HUF}]}\end{array}$ & $\begin{array}{c}\text { Cost } \\
\text { saving of } \\
\text { remaining } \\
\text { fuel at last } \\
\text { station } \\
{[\text { HUF }]}\end{array}$ \\
\hline $\begin{array}{l}\text { Non-optimal } \\
\text { solution } \\
\text { (Figure 11) }\end{array}$ & 54423 & 139.88 & 376 & 76.97 & 28940 & \\
\hline $\begin{array}{l}\text { Optimal } \\
\text { solution } \\
\text { (Figure 9) }\end{array}$ & 50800 & 73 & 336 & 11.12 & 3736 & \\
\hline Cost saving & $\begin{array}{c}3623 \\
(-6.66 \%)\end{array}$ & & & & & 5004 \\
\hline $\begin{array}{l}\text { Total cost } \\
\text { saving }\end{array}$ & $\begin{array}{c}8627 \\
(-15.85 \%)\end{array}$ & & & & & \\
\hline
\end{tabular}

TABLE 1. Comparison of optimal and non-optimal solutions. Note: the cost saving resulted by the remaining fuel can be calculated from the difference of volumes of remaining fuel in case of optimal and non-optimal cases (65.85 litres) and the difference of fuel price at the non-optimal station $(376 \mathrm{HUF} /$ litre $)$ and the fuel price at the depot of the transport company (300 HUF/litre).

It can be concluded that if the decision making of the driver could be supported by our software, the total cost of the transport way can be reduced significantly.

\section{Communication BETWEEN VEHICLES AND THE DISPATCH STATION}

The developed software is installed at the dispatch station. Based on the information provided by the software, the drivers can make the best decision relating to refuelling and the total costs of the transport trip can be minimized. A two-way communication system has to be formed in which vehicles can communicate with a dispatch station, providing each other with information. The vehicle has to provide the required information on-line for the optimal route planning and selection of the optimal fuel station. These data are the following: the actual GPS position of the vehicle, actual fuel amount of the vehicle, actual fuel consumption, etc. The decisions calculated by the planning software can also be transferred to the mobile vehicle.

Figure 12 shows the operation and the system elements of the two-way communication, which involves feedback from the receiver to the sender.

\section{Elements of the communication system.}

(1.) GPS system for detecting the vehicle's position with the help of satellites.

(2.) Communication channel for double direction communication between vehicles and the dispatch station. This data communication is based on GPRS.

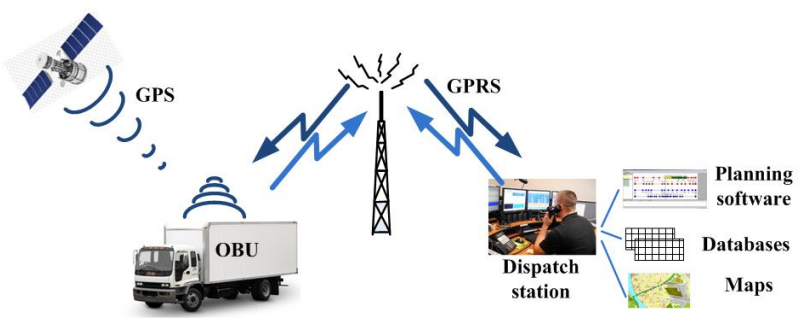

FiguRE 12. Vehicle to dispatcher communication.

(3.) On Board Unit (OBU) which is a communication device mounted in the vehicle. It allows the two-way GPRS communication of vehicles with the dispatch station. The OBU is available for collecting actual data related to the vehicle, e.g. actual fuel amount of the vehicle, actual fuel consumption, etc.

(4.) Dispatch station comprising:

- Planning software at the dispatch station for calculating and visualizing the optimal transport route. The transport manager can define or reconfigure the optimal transport routes and select the optimal petrol station.

- Database for the properties of the vehicles (capacity, fuel consumption, etc.), part of the software.

- Database for actual fuel prices at the different petrol stations, also part of the planning software.

- Digital (vector graphical) map database with important defined points (POI), e.g. preferred petrol stations, frontier stations, parking places, etc.; part of the planning software. 


\section{Conclusion}

Transportation is one of the most expensive logistical activities; therefore, carriers and forwarding agents put great emphasis on the optimization of the road transportation and reduction of the transport costs, especially the reduction of the fuel costs.

The topic of the research is the fuel cost reduction; therefore, the study is very important and relevant.

Recently, in practice, the selection of the petrol station for refuelling and the amount of the refilled fuel have not been determined centrally at most transport companies; they are not supported by software, but depend on the individual decision of drivers. The result of wrong decisions is that the cost of the consumed fuel is not optimal.

During the research, an absolutely new and unique mathematical model and method was elaborated for optimizing the road transport activity both by selecting the optimal petrol station (depending on the fuel price and distance to the original transport way) and by determining the optimal quantity of the amount of the refilled fuel (only the required amount of the fuel, not more). This method can result in significant cost savings, mainly in the case of international routes, when a high amount of fuel is consumed. This is the reason why this research is important.

Based on the precise and reliable mathematical model and method, unique software was developed, which can be used very efficiently and widely in practice for everyday use. Further advantages of the software are that it absolutely suits the customer demands and it is very cost effective.

In this study, the fuel cost reduction was showed in a case study by a comparative analysis (Section 8). It can be concluded that the fuel costs of the road transport trips can be reduced significantly by applying the developed software.

\section{REFERENCES}

[1] Bookbinder, H. J. (Editor): Handbook of Global Logistics, Transportation in International Supply Chains. Springer, 2013.

[2] Kovács, Gy., Kot, S.: New logistics and production trends as the effect of global economy changes. Polish Journal of Management Studies, 14(2), 2016, p. 115-126.
[3] Fraunhofer Institute: Executive summary. 2015. http://www.scs.fraunhofer.de/content/dam/scs/ de/dokumente/studien/Top $\% 20100 \% 20$ EU $\% 202015 \%$ 20Executive\%20Summary.pdf [2017-06-30].

[4] Ross, D. F.: Distribution Planning and Control. Springer, 2015.

[5] Lukinskiy, V., Dobromirov, V.: Methods of evaluating transportation and logistics operations in supply chains. Transport and Telecommunication, 17(1), 2016, p. 55-59.

[6] Mocková, D.: Allocation and Location of Transport Logistics Centres. Acta Polytechnica, 50 (1), 2010, p. 30-34.

[7] Birge, J. R., Linetsky, V.: Handbooks in Operations Research and Management Science. North Holland, 2007.

[8] Simchi-Levi, D., Xin, C., Bramel, J.: The Logic of Logistics, Theory, Algorithms, and Applications for Logistics Management. Springer, 2014.

[9] Anbuudayasankar, S. P., Ganesh, K., Mohapatra, S.: Models for Practical Routing Problems in Logistics. Design and Practices. Springer, 2014.

[10] Sinha, K. C., Labi S.: Transportation decision making. John Wiley\&Sons Inc., 2007.

[11] Caramia, M., Dell'Olmo, P.: Multi-objective management in freight logistics. Springer, 2008.

[12] Rushton, A.; Croucher, P.; Baker, P.: The Handbook of Logistics \& Distribution Management. Kogan Page Limited, 2010.

[13] Ehmke, J. F.: Integration of information and optimization models for routing in city logistics. Springer, 2012.

[14] Kovács, Gy., Cselényi, J.: Utilization of historic data evaluation obtained from computer database during the organization of international transport activity. In: Proceedings of 2nd Conference with International Participation Management of Manufacturing Systems, Presov, Slovakia, 2006, p. 18.

[15] Cziczer, N.: Optimal design of refuelling method for Hungarian road freight transport activity (in Hungarian), Graduation thesis, University of Miskolc, 2016.

[16] Reiter, I.: C\# technologies (in Hungarian). 2010. http://devportal.hu/download/E-bookok/csharp\% 20jegyzet/csharp.pdf [2017-06-30]. 